\title{
The development and application of passive architecture in China
}

\author{
Ning Zhang ${ }^{1}, \mathrm{Yu} \mathrm{Bi}^{2}$ \\ ${ }^{1}$ School of Architecture and Design, Changchun Institute of Technology, Changchun, Jilin Province, 130000, China \\ ${ }^{2}$ ChangChun Finance College, Changchun, Jilin Province, 130000, China
}

\begin{abstract}
Passive buildings can achieve energy saving goals through their own spatial form, envelope, building materials and structural design. However, at present, there are many problems in the development of passive buildings in China, such as inadequate foundation, unreasonable passive design, which make the development of passive buildings have many obstacles, not conducive to the promotion of the construction industry. Therefore, this paper analyzes the obstacle factors of passive buildings and puts forward reasonable solutions for reference.
\end{abstract}

\section{Introduction}

According to the report on building energy efficiency released by China building energy conservation association in 2016, the total energy consumption of buildings is 899 million tons of standard coal, accounting for $20.6 \%$ of the total energy consumption in China, and the total carbon emission of buildings is 1.96 billion tons of $\mathrm{CO} 2$, accounting for $19.4 \%$ of the total energy carbon emission in China. Passive buildings can provide people with comfortable indoor environment and reduce energy consumption of artificial energy supply to the greatest extent through the building itself. However, in the implementation of passive buildings, due to technical limitations, there are many obstacles. Therefore, it is necessary to strengthen research efforts and formulate reasonable solutions to improve the development level of China's construction industry and reduce energy consumption.

\section{Advantages of passive building design implementation}

Passive architectural design is mainly to make the indoor temperature environment of the building get rid of the traditional active energy supply through reasonable design, minimize the consumption of non-renewable energy, and promote the external environment to actively maintain the temperature and environment inside the building. The biggest feature of this architectural design is the use of the surrounding renewable energy to design the building, such as the use of solar, wind, water and other renewable energy. Solar energy is used for heating and heating, and natural wind energy is used for ventilation of buildings to create a livable environment for people, so that people can live in harmony with nature and promote the steady progress of modern society.

\section{Analysis of obstacles to the development of passive buildings in China}

\section{1 insufficient development momentum}

Passive buildings require designers to make comprehensive decisions at the early stage of the project by combining climate, terrain and other factors. Based on the research of the passive building design understands, passive construction development in our country is still in its infancy, lack of scientific and perfect theory system and evaluation standard. And coupled with differences in climate and the technical standards at home and abroad, makes passive construction lack of information, which can be used for reference in the process of development theory system construction is not mature. In addition, due to the lack of publicity, enterprises to its poor recognition, market acceptance is low.

\subsection{Lack of relevant supporting building materials}

Compared with ordinary buildings, passive buildings pay more attention to the performance and quality of materials. Taking building thermal insulation as an example, building doors, Windows, walls and other external envelope are not only to meet the thermal insulation requirements, thermal insulation, but also need a certain waterproof, fire resistance, and to meet the service life. Therefore, it is difficult for many building materials manufacturers in China to provide products that can meet the requirements of passive building standards due to relevant factors such as production technology, material technology and production cost, and even the

\footnotetext{
*Corresponding author's e-mail: 826490544@qq.com
} 
phenomenon of industry concentration and unclear scientific and technological demonstration [1].

\subsection{Passive design is not paid enough attention}

At present, China is in the early stage of passive architecture development, many people are not familiar with the concept of passive architecture, and have never come into contact with passive architecture. Although China currently attaches great importance to energy conservation and emission reduction, its main goal is to improve the utilization rate of conventional energy and develop new energy, and the time of passive buildings is relatively short. In addition, China's current building energy-saving design standards do not require passive design, so most architectural designers prefer to choose active design in the design process. China's first publication on passive buildings appeared in 2016. Recently, some provinces and cities in China have just introduced supportive policies for passive buildings, but relevant departments cannot vigorously promote the development of passive buildings [2].

\section{Countermeasures to promote the development of passive buildings}

Passive technology and active technology are not mutually contradictory, and low technology and high technology are not mutually exclusive. The passive technology starts from economy, the active technology starts from efficiency, the low technology focuses on protection, and the high technology focuses on development. They are independent technological thinking, principles and systems, and they are closely related, complementary and complementary.

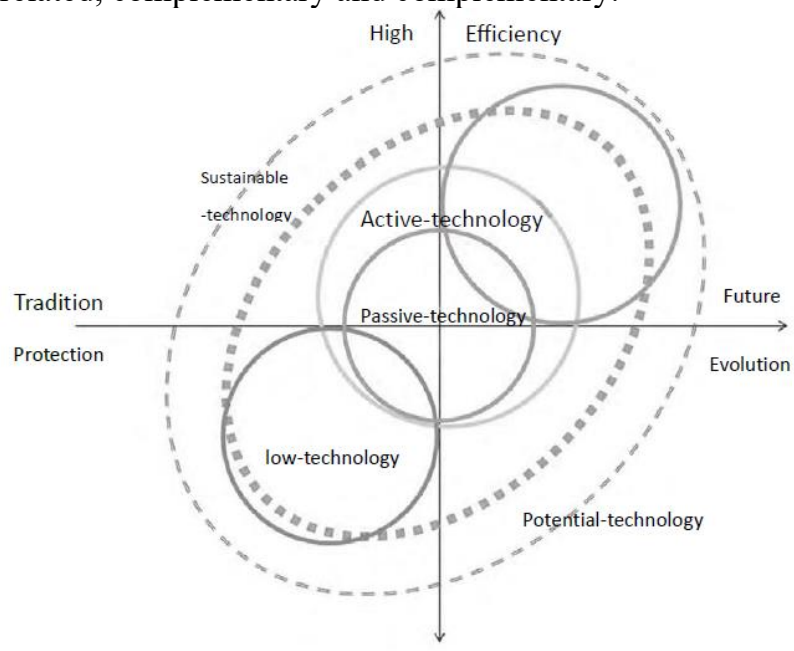

Figure 1. Technical diagram of sustainable relationships in architecture

\subsection{Drive to stimulate the development of passive buildings}

\section{1) Strengthen theoretical research}

First, the government should increase financial expenditure and provide sufficient research funds for researchers. Secondly, the government needs to conduct policy guidance to stimulate the initiative of research institutions and related enterprises to participate in the research. Thirdly, effective measures should be taken to promote the cooperation between enterprises, universities and research institutes so as to lay a solid foundation for industrial development. Finally, the development of passive building market is constantly promoted, and the integration of theory and practice is realized on the basis of market regulation[3].

2) Improve professional skills

At present, the development of passive buildings abroad has made a substantial breakthrough, and the professional technology is becoming more and more perfect and mature. Therefore, in the process of domestic and foreign project cooperation and technical exchange, it is necessary to actively introduce foreign advanced technology ideas and forms.

Passive buildings have high standards for material quality and expertise. For example, the ductility, compactness and durability of the sealing material for the outer window frame, as well as the strength, corrosion resistance and durability of the hardware fittings are more prominent. The improvement of construction technology level and the intensification of construction quality supervision make the quality problems of passive construction link less and less, at the same time, it also greatly guarantees the quality and safety of the project. In addition, on the premise of constantly improving professional technology, it is necessary to strengthen the standardized management of the construction industry, which is of great significance for the sustainable development of the whole passive construction industry.

\subsection{Improve passive architectural design methods}

Passive buildings mainly start from buildings. Under the background of making full use of the surrounding natural environment, they provide users with a comfortable environment and reduce building energy consumption through reasonable layout planning, selection of appropriate structure types, and well-designed body structure, etc. [4].

1) Scientific site selection and reasonable layout

In the site selection, the existing conditions of the terrain should be fully considered, and reasonable building orientation, building form, building shape coefficient, etc., should be designed to receive or block the sunlight, use or prevent the dominant wind direction, increase or decrease the temperature and humidity. Make the building and its surrounding environment form a self-circulation system as much as possible, reduce the energy supply of active mechanical equipment, achieve energy saving and achieve the effect of sustainable development.

\section{2) Strengthening envelope design}

The design of building envelope is the weak link of building thermal engineering, which mainly involves doors and Windows, walls, roofs and other parts. As the part with the largest area in the outer protective structure, 
the wall is the key part of building energy conservation. Under the condition of certain materials, the heat preservation method usually used for passive building walls can play an important role in wall energy consumption.

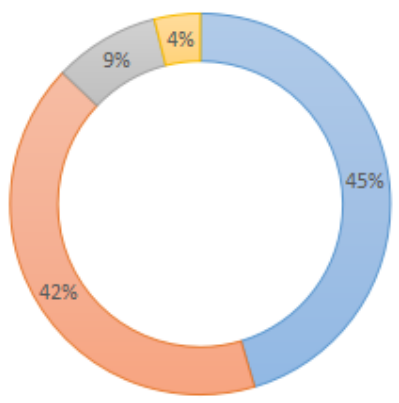

$\square$ The wall $\square$ External window $\square$ The roof $\square$ Anteport

Figure 2. The proportion of heat loss in each part of building envelope in Beijing

As an important part of the envelope structure, the roof can make use of or block the solar radiation. The energy saving efficiency of the roof is directly related to the energy consumption level of the room on the top floor. Doors and Windows are the key part of direct heat exchange between indoor and outdoor, and also the weak part of the envelope, whose thermal resistance is much lower than that of the wall. Compared with walls, roofs and other parts, the heat loss of doors and Windows is the greatest. In addition to the use of high-quality energy-saving doors and Windows, in order to better improve the thermal insulation performance of buildings, the ratio of Windows and walls should be appropriately adjusted according to the climate characteristics of the region, so as to make full use of natural energy such as solar energy and wind energy and reduce the energy consumption of buildings [5].

\section{The conclusion}

To sum up, in the new era background, the passive construction industry to flourish, to this end, it is necessary to strengthen the passive construction technology research, and develop a series of macroscopic policy support, security, main market supply and demand balance, to promote the stable development of the whole passive construction industry, to the construction industry in our country add vitality.

\section{Acknowledgment}

This work was financially supported by Science and Technology Project Foundation of Jilin Provincial Development and Reform Commission (No. 2019C059-4), Science and Technology Project Foundation of Jilin Provincial Department of Education (No. JJKH20191242KJ) and Jilin Provincial Social Science Foundation.

\section{References}

1. Yang guang, liu qinghua. Research on constraints and countermeasures for the development of passive buildings in China [J]. Urban architecture.2015(22)

2. song qi, Yin baogang, Yang liu. Analysis of obstacles and countermeasures to the development of passive buildings in China $[\mathrm{J}]$. Construction economy.2014, (01):9-11.

3. Chen hua-jin, li baojun, dong zhifeng. Discussion on passive energy saving design of buildings [J]. China construction news.2007(03).

4. Wei yuanyuan. Research on application strategy of passive energy saving technology in building renovation [D]. Zhejiang university,2015.

5. LanKun, zhangze Hao. Passive energy saving design strategy of cold region school architecture. Architecture and culture. 2016 (7).

6. Yunting Gao. Research on technology strategy in sustainable building design. Energy saving in construction industry.2019,12-0029-04.

7. Jianmin $\mathrm{Xu}$. Discussion on the key points of passive building design for energy saving in construction industry. Architecture.2019-19 